\title{
Factors associated with the myth about 5G network during COVID-19 pandemic in sub-Saharan Africa
}

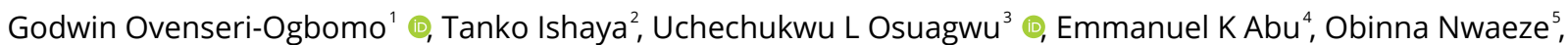
Richard Oloruntoba ${ }^{6}$, Bernadine Ekpenyong ${ }^{7}$, Khathutshelo P Mashige $^{8}$, Timothy Chikasirimobi ${ }^{9}$, Raymond Langsi ${ }^{10}$, Deborah D Charwe ${ }^{11}$, Kingsley Agho ${ }^{12}$

${ }^{1}$ Department of Optometry, Faculty of Life Sciences, University of Benin, Benin City, Nigeria; Department of Optometry, College of Applied Medical Sciences, Qassim University, Saudi Arabia; African Eye and Public Health Research Initiative, African Vision Research Institute, Discipline of Optometry, University of KwaZulu-Natal, Westville Campus, Durban, 3629, South Africa, ${ }^{2}$ Department of Computer Science, University of Jos, Nigeria, ${ }^{3}$ Diabetes, Obesity and Metabolism Translational Research Unit, Western Sydney University, Campbelltown, NSW 2560, Australia; African Eye and Public Health Research Initiative, African Vision Research Institute, Discipline of Optometry, University of KwaZulu-Natal, Westville Campus, Durban, 3629, South Africa, ${ }^{4}$ Department of Optometry and Vision Science, School of Allied Health Sciences, University of Cape Coast, Ghana, 5 NHS, United Kingdom, 6 School of Management, Curtin Business School Bentley, Western Australia, ${ }^{7}$ Department of Public Health, Faculty of Allied Health Sciences, College of Medical Sciences, University of Calabar, Cross River State, Nigeria; African Eye and Public Health Research Initiative, African Vision Research Institute, Discipline of Optometry, University of KwaZulu-Natal, Westville Campus, Durban, 3629, South Africa, 8 Discipline of Optometry, University of KwaZuluNatal, Westville Campus, Durban, 3629, South Africa; African Eye and Public Health Research Initiative, African Vision Research Institute, Discipline of Optometry, University of KwaZulu-Natal, Westville Campus, Durban, 3629, South Africa, ${ }^{9}$ Department of Optometry, Masinde Muliro University of Science and Technology, Kakamega Kenya, ${ }^{10}$ Health Division, University of Bamenda ,Bambili ,Cameroon, ${ }^{11}$ Tanzania Food and Nutrition Center, P.O.Box 977 Dar es Salaam, Tanzania, ${ }^{12}$ School of Health Science, Western Sydney University, Campbelltown, NSW 2560, Australia

Keywords: $5 \mathrm{~g}$ technology, sub-saharan africa, covid-19

https://doi.org/10.29392/001c.17606

\section{Journal of Global Health Reports}

Vol. 4, 2020

\section{Background}

Globally, the conspiracy theory claiming $5 \mathrm{G}$ technology can spread the coronavirus disease (COVID-19) is making the rounds on social media and this could have a significant effect in tackling the spread of the pandemic. This study investigated the impact of the myth that $5 \mathrm{G}$ technology is linked to COVID-19 pandemic among sub-Saharan Africans (SSA).

\section{Methods}

A cross-sectional survey was administered on 2032 participants between April 18 - May 16,2020 , corresponding to the mandatory lockdown period in some SSA countries (April 18 - May 16, 2020). Participants were recruited via Facebook, WhatsApp, and authors' emails. The outcome measure was whether respondent believed that $5 \mathrm{G}$ technology was the cause of the coronavirus outbreak or not. Multiple logistic regression analyses using backward stepwise were used to examine the associated factors.

\section{Results}

About $7.3 \%$ of the participants believed that $5 \mathrm{G}$ technology was behind the COVID-19 pandemic. Participants from Central Africa reported the highest proportion (14.4\%) while the lowest proportion (5.4\%) was among those from Southern Africa. After adjusting for potential covariates in the multivariate analysis, Central Africans (adjusted odds ratio, AOR 2.12; 95\% confidence interval, $\mathrm{CI}=1.20-3.75$ ), females (AOR 1.86; 95\% CI=1.20-2.84) and those who were unemployed at the time of this study (AOR 1.91; 95\% CI=1.08-3.36) were more likely to believe in the myth that $5 \mathrm{G}$ technology was linked to the COVID-19 pandemic. Participants who felt that COVID-19 pandemic will not continue in their country were 1.59 times $(95 \% \mathrm{CI}=1.04-2.45)$ more likely to associate the $5 \mathrm{G}$ technology with COVID-19 compared to those who thought that the disease will remain after the lockdown. Participants who were younger were more likely to believe in the $5 \mathrm{G}$ technology myth but the association between level of education and belief that $5 \mathrm{G}$ technology was associated with COVID-19 which was significant in the univariate analysis (unadjusted odds ratio OR 1.69; 95CI =1.02, 2.80), was nullified after adjustments for all potential confounders.

\section{Conclusions}

This study found that $7.4 \%$ of adult participants from SSA held the belief that $5 \mathrm{G}$ technology was linked to COVID-19 pandemic. Public health interventions including 
health education strategies to address the myth that $5 \mathrm{G}$ was linked COVID-19 pandemic in SSA are needed and such intervention should target participants who do not believe that COVID-19 pandemic will continue in their country, females, those that are unemployed and those from Central African countries in order to minimize further spread of the disease in the region.

During the outbreak of the novel coronavirus disease (COVID-19) and the subsequent global spread of the pandemic, there arose a myth that the outbreak was associated with the fifth generation mobile telecommunication technology, known as 5G. ${ }^{1}$ Holding such myths could have implications for compliance with non-pharmaceutical preventive strategies prescribed for the control of the novel coronavirus. ${ }^{2}$ These myths include that $5 \mathrm{G}$ was the cause of the novel coronavirus; that the electromagnetic radiation from the $5 \mathrm{G}$ technology was responsible for the mutation of the coronavirus; and that the $5 \mathrm{G}$ technology was a strategy of the industrialized nations to control the population of the less industrialized nations among others. ${ }^{2-4}$ This is because of the fact that radiofrequency radiation $(\mathrm{RF})$ is increasingly being identified as a new form of environmental pollution. ${ }^{3}$

The fifth generation mobile telecommunication is the new, high-speed wireless communications technology, promising faster bandwidth speeds of $1-10 \mathrm{Gbps}$, wider coverage, reduced congestion and improved latency. ${ }^{4}$ The technology is expected to be transformative, fueling innovation across every industry and every aspect of our lives. The combination of its high-speed and potential to transform the human way of life by fully supporting the implementation of Internet-of-things (IoT) solutions generated various myths about $5 \mathrm{G}$.

Whereas myths are usually associated with individuals who may be unlearned in the subject matter, the myths of the harmful effects of $5 \mathrm{G}$ have been promoted by some scientists. ${ }^{1}$ The evidence for the biological effects of mobile phone technology and non-ionizing radiofrequency used in the $5 \mathrm{G}$ technology are inconclusive at present. ${ }^{4-9}$ While available research till date, do not reveal any adverse health effect being causally linked with exposure to wireless technologies ${ }^{10}$ further health related studies need to be carried out at the frequencies to be used by $5 \mathrm{G}$. Notwithstanding the lack of evidence to support the link between the $5 \mathrm{G}$ technology and the pandemic, the myth has continued to grow globally. Besides the myth linking $5 \mathrm{G}$ technology with coronavirus, several other myths have been held regarding COVID-19. ${ }^{11}$

South Africa and Lesotho are the only countries in subSaharan Africa that have launched the $5 \mathrm{G}$ technology with limited coverage. ${ }^{12}$ Notwithstanding, the myths about the association of the technology with the outbreak of COVID-19 continue to be held in sub-Saharan Africa. Myths (unsubstantiated beliefs) ${ }^{13,14}$ held by individuals have played a significant role in public health interventions including acceptance of immunization and use of preventive health strategies. ${ }^{15-18}$

As the novel coronavirus outbreak assumed pandemic proportion, and as a result of lack of treatment and vaccine for the disease several community directed strategies are recommended to contain and mitigate the outbreak. Some of the recommended strategies include international and local travel restrictions, quarantine and self-isolation of suspected cases for a period equivalent to the incubation period of the disease (maximum 14 days), lockdown of commercial activities in major cities, closure of schools, restriction of movement, frequent hand washing, use of face masks and social distancing. ${ }^{19}$ It is widely believed that the spread of the virus in the community can be minimized if citizens follow these recommendations and practices.

There have been concerns with the level of compliance with these preventive strategies in sub-Saharan African (SSA) countries. Using the health belief model (HBM) it has been postulated that behavior and perception influence the development of preventive health behavior. ${ }^{20}$ This study was designed to examine factors associated with the myth that 5G technology was linked to COVID-19 pandemic. Findings from this research will enable researchers and policy makers target sub-population who will not comply with preventive measures proposed for the mitigation of the present pandemic and any other outbreaks when myths held by these sub-populations are the reasons for non-compliance.

\section{METHODS}

A cross-sectional descriptive study was conducted between April 18 and May 16, 2020 when most of the countries surveyed were under mandatory lockdown and restriction of movement. As it was not feasible to perform nationwide community-based sample survey during this period, the data were obtained electronically via survey monkey. Only participants who had access to the internet, were on the respective social media platforms and used them, may have participated. An e-link of the structured synchronized questionnaire was posted on social media platforms (Facebook and WhatsApp) which were commonly used by the locals in the participating countries, and was sent via emails by the researchers to facilitate response. The questionnaire included a brief overview of the context, purpose, procedures, nature of participation, privacy and confidentiality statements and notes to be filled out.

\section{STUDY POPULATION}

The participants were sub-Saharan African nationals from different African countries either living abroad or in their countries of origin including Ghana, Cameroun (only distributed to the English speaking regions), Nigeria, South Africa, Tanzania, Kenya, Uganda etc. To be eligible for participation, participants had to be 18 years and over, and should be able to provide online consent.

\section{SURVEY QUESTIONNAIRE}

The survey tool for the COVID-19 knowledge questionnaire was developed based on the guidelines from the World Health Organization (WHO) for clinical and community management of COVID-19. The questionnaire was adapted 
Table 1. Covariates used in the multiple logistic regression

\begin{tabular}{|c|c|c|c|}
\hline Model 1 & Model 2 & Model 3 & Model 4 \\
\hline $\begin{array}{l}\text { Region*and Socio- } \\
\text { demographic }\end{array}$ & $\begin{array}{l}\text { Region*and Socio- } \\
\text { demographicp }\end{array}$ & $\begin{array}{l}\text { Region*and Socio- } \\
\text { demographic and attitudep }\end{array}$ & $\begin{array}{l}\text { Region*and Socio-demographic and } \\
\text { attitude and Compliancep }\end{array}$ \\
\hline Place of residence & $\begin{array}{l}\text { Attitude towards } \\
\text { Covid-19 }\end{array}$ & $\begin{array}{l}\text { Compliance during lockdown } \\
\text { during Covid }-19\end{array}$ & Covid-19 risk perception $\$$ \\
\hline Age in years & Self-Isolation & $\begin{array}{l}\text { Attended crowded religious } \\
\text { events }\end{array}$ & Risk of becoming infected \\
\hline Sex & $\begin{array}{l}\text { Home quarantined } \\
\text { due to Covid-19 }\end{array}$ & Wore mask when going out & Risk of becoming severely infected \\
\hline Marital Status & & $\begin{array}{l}\text { Practiced regular Hand } \\
\text { washing }\end{array}$ & Risk of dying from the infection \\
\hline $\begin{array}{l}\text { Highest level of } \\
\text { Education }\end{array}$ & & & $\begin{array}{l}\text { How much worried are you about } \\
\text { COVID-19 }\end{array}$ \\
\hline Employment status & & & $\begin{array}{l}\text { How likely do you think Covid-19 will } \\
\text { continue in your country }\end{array}$ \\
\hline Religion & & & $\begin{array}{l}\text { Concern for self and family if COVID-19 } \\
\text { continues }\end{array}$ \\
\hline \multicolumn{4}{|l|}{ Occupation } \\
\hline $\begin{array}{l}\text { Number living } \\
\text { together }\end{array}$ & & & \\
\hline
\end{tabular}

* West Africa, East Africa, Central Africa \& Southern Africa;

$\$$ High/very worried/very concerned/very likely for "High/ Concerned/worried \& Very High/Extremely Concerned/extremely worried" \& Low/ not worried/ not concerned/no very likely for" Very low/Not at all/Very unlikely/ Extremely unconcerned; Unlikely/Unconcerned/ A little \& Neither likely nor unlikely/moderate/ Neither Concerned nor Unconcerned $\mathrm{p}=$ only significant variables were added.

with some modifications to suit this study's objective, namely to explore the potential impact of the myth about the $5 \mathrm{G}$ technology on compliance with strategies to control the spread of the novel coronavirus.

Prior to launching of the survey, a pilot study was conducted to ensure clarity and understanding as well as to determine the duration for completing the questionnaire. Participants $(n=10)$ who took part in the pilot were not part of the research team and did not participate in the final survey as well. This self-administered online questionnaire consisted of 58 items divided into four sections (demographic characteristics, knowledge, attitude, perception and practice). Online Supplementary Document Table $S 1$ is a sample of the tables showing the items used in the data analysis.

\section{DEPENDENT VARIABLE}

The dependent variable for this study was Myth about the $5 \mathrm{G}$ technology which was categorized as "Yes" $(1=$ if COVID-19 is associated with $5 \mathrm{G}$ communication) or "No" (0 $=$ if COVID-19 is not associated with $5 \mathrm{G}$ communication).

\section{INDEPENDENT VARIABLES}

The independent variables were: a) demographic characteristics of the participants which included age, country of origin, country of residence, sex, religion, educational, marital and occupational status; b) attitude towards COVID-19 which included practice of self-isolation, home quarantine, number of people living together in the household; c) compliance during COVID-19 lockdown which included whether they attended a crowded event, used face mask when going out, practiced regular hand-washing, used hand sanitizers; and d) risk perception which included whether participants think they were at risk of becoming infected, at risk of dying from the infection, if they were worried about contracting COVID-19, and thought the infection will continue in their country (Table 1).

\section{DATA ANALYSIS}

Demographic, compliance during lockdown, attitude and perception variables were summarized as counts and percentages for categorical variables. A two-way frequency table was used to obtain the proportion estimates of those who reported that 5G technology was linked to COVID-19. In the univariate and bivariate analyses, Odds ratios with 95\% confidence intervals were calculated in order to assess the unadjusted risk of independent variables on selected covariates.

In the univariate logistic regression analysis, variables with a $\mathrm{p}$-value $<0.20$ were retained and used to build a multivariable logistic regression model which examined the factors associated with the myth about $5 \mathrm{G}$ technology during COVID-19 pandemic. Similarly, we performed a stage modeling technique employed by Dibley et al., ${ }^{21}$ and a fourstaged modeling technique was employed. In the first stage, regions and demographic factors were entered into a baseline multivariable model. We then conducted a manually executed elimination method to determine factors associated with the myth about $5 \mathrm{G}$ technology during COVID-19 pandemic at $\mathrm{P}<0.05$. The significant factors in the first stage were added to attitude towards COVID-19 variables in 
the second staged model; this was then followed by manually executed elimination procedure and variables that were associated with the study outcomes at $\mathrm{P}<0.05$ were retained in the model. We used a similar approach for compliance to public health measures and COVID-19 risk perception factors in the third and fourth stages, respectively. The odds ratios with $95 \%$ confidence intervals were also calculated to assess the adjusted factors. All analyses were performed in Stata version 14.1 (Stata Corp, College Station, Texas, USA).

\section{ETHICAL CONSIDERATION}

Ethical approval for the study was sought and obtained from the Human Research Ethics Committee of the Cross River State Ministry of Health (CRSMOH/HRP/HREC/2020/117). The study was carried out in accordance with the Helsinki Declaration for Human Research. The confidentiality of participants was assured in that no identifying information was obtained from participants and informed consent was obtained from all participants prior to completing the survey. Participants were required to answer a 'yes' or 'no' to the consent question during survey completion to indicate their willingness to participate in this study.

\section{RESULTS}

\section{DEMOGRAPHY OF PARTICIPANTS}

Table 2 shows the descriptive data of the participants. Of the 1969 participants that indicated their country of residence, majority $(n=1,108,56.3 \%)$ were from West Africa and few from East Africa $(\mathrm{n}=209,10.6 \%)$. Over $65 \%$ of the participants were aged 38 years or younger and $55.2 \%$ were males. More than two-third of the participants (79.2\%) had at least a Bachelor degree while $20.8 \%$ had either a secondary or primary (basic) school education. About $52 \%$ were living with $4-6$ persons during the study period while $18.6 \%$ lived alone.

\section{PERSPECTIVE OF SUB-SAHARAN AFRICANS ON 5G TECHNOLOGY AND COVID-19}

The belief that 5G technology was linked to the COVID-19 pandemic was upheld by $7.4 \%$ of the participants in this study, and some participants $(31.3 \%)$ stated that they practiced self-isolation while $39.3 \%$ practiced home quarantine during the pandemic. Responding to the question of how worried they were about COVID-19, over $57 \%$ of the participants stated that they were either very worried or somehow worried about the disease (Table 2). During the COVID-19 lockdown in SSA, nearly half (46\%) of the participants in the study attended crowded religious events and a majority (76.1\%) wore a mask when going out.

Figure 1 shows the regional proportion and 95\% confidence intervals of the proportion of participants in this study who believed 5G technology was behind the COVID-19 pandemic in Sub-Saharan Africa. According to the figure, Central Africa had the highest proportion (14.4\%) of participants that believed in the $5 \mathrm{G}$ technology myth while few participants (5.4\%) from Southern Africa believed in the $5 \mathrm{G}$ technology myth.

Table 3 reports the proportion and unadjusted odds ratio
(OR) as well as the 95\% confidence interval of the odds ratio that $5 \mathrm{G}$ technology was associated with COVID-19. The unadjusted odd ratios revealed that participants from Central African countries, female participants, those who were not married and unemployed, and participants with primary/secondary education qualification, were more likely to believe that $5 \mathrm{G}$ technology was linked to the COVID-19 disease. Compared with the younger age group (age 18-28 years), older participants (29 to 48 years) were less likely to believe that $5 \mathrm{G}$ technology was linked to the COVID-19 pandemic while, those who perceived that COVID-19 was less likely to continue in their country were 1.50 times (95\% confidence interval of unadjusted odds ratio $1.05-2.15$ ) more likely to believe that $5 \mathrm{G}$ technology was linked to COVID-19 pandemic (see Table 3).

Table 4 shows the independent predictors of the association between $5 \mathrm{G}$ technology and COVID-19 disease. Participants who were living in Central Africa, females, and those who were unemployed at the time of this study were more likely to associate $5 \mathrm{G}$ technology with COVID-19. Also, belief in the $5 \mathrm{G}$ technology myth was associated with participants' level of risk perception, such that those who felt that the disease was not going to continue in their various countries after the lockdown were more likely to associate $5 \mathrm{G}$ technology with COVID-19 disease (adjusted odds ratio (aOR) 1.57, 95\% confidence interval, $\mathrm{CI}=1.07-2.31$ ) compared with those who felt that the disease was more likely to remain in their respective countries after the lockdown. Participants with low risk perception of contracting the infection, and those who were aged 39-48 years were less likely to associate $5 \mathrm{G}$ technology with COVID-19 compared with those who had high risk perception of contracting the infection and younger participants, respectively.

\section{DISCUSSION}

To the best of our knowledge, this is the first study from SSA to examine key factors associated with the myth about $5 \mathrm{G}$ technology and COVID-19 as well as how this myth influences compliance with prescribed behavioral measures to control the spread of the disease. The study found that, irrespective of whether participants were living within the subregion or in the diaspora, nearly $7.4 \%$ of participants from SSA believed that $5 \mathrm{G}$ technology was linked with the outbreak of COVID-19. This was more among those from Central African and East African countries, where the proportions were $14 \%$ and $8 \%$, respectively. After adjusting for all potential cofounders, participants from Central Africa, females, those that were unemployed and individuals in this study who thought that COVID-19 was not going to continue in their countries after the lockdown, were more likely to hold this myth. There was a consistent strong association between older age (39-48yrs) and the lower likelihood of believing in the $5 \mathrm{G}$ myth. Perception of risk of contracting the infection was associated with the belief in the $5 \mathrm{G}$ myth.

The findings of this study were in concordance with a study conducted in England which reported that about 10 - $15 \%$ of the participants showed constant and very high levels of endorsements of the myth and those who believed that $5 \mathrm{G}$ technology was linked with the COVID-19 pandemic were less likely to comply with government preventive 
Table 2: Respondent characteristics and study variables

\begin{tabular}{|c|c|}
\hline Variables & $N(\%)$ \\
\hline \multicolumn{2}{|l|}{ Demography } \\
\hline \multicolumn{2}{|l|}{ Region } \\
\hline West Africa & $1,108(56.3)$ \\
\hline East Africa & $209(10.6)$ \\
\hline Central Africa & $251(12.7)$ \\
\hline Southern Africa & $401(20.4)$ \\
\hline \multicolumn{2}{|l|}{ Place of residence } \\
\hline Locally (Africa) & $1855(92.5)$ \\
\hline Diaspora & $150(7.5)$ \\
\hline \multicolumn{2}{|l|}{ Age category } \\
\hline $18-28$ years & $775(39.0)$ \\
\hline $29-38$ years & $530(26.7)$ \\
\hline $39-48$ years & $441(22.2)$ \\
\hline 49+years & $242(12.1)$ \\
\hline \multicolumn{2}{|l|}{ Sex } \\
\hline Males & $1099(55.2)$ \\
\hline Females & $892(44.8)$ \\
\hline \multicolumn{2}{|l|}{ Marital status } \\
\hline Married & $879(44.1)$ \\
\hline Not married & $1116(55.9)$ \\
\hline \multicolumn{2}{|l|}{ Highest level of Education } \\
\hline Postgraduate Degree (Masters /PhD) & $642(32.2)$ \\
\hline Bachelor's degree & (939) 47.0 \\
\hline Secondary/Primary & $416(20.8)$ \\
\hline \multicolumn{2}{|l|}{ Employment status } \\
\hline Employed & $1321(66.0)$ \\
\hline Unemployed & $679(34.0)$ \\
\hline \multicolumn{2}{|l|}{ Religion } \\
\hline Christianity & $1763(88.4)$ \\
\hline Others & $232(11.6)$ \\
\hline \multicolumn{2}{|l|}{ Occupation } \\
\hline Non-health care sector & $1,471(77.3)$ \\
\hline Health care sector & $433(22.7)$ \\
\hline \multicolumn{2}{|l|}{ Number living together } \\
\hline$<3$ people & $506(28.8)$ \\
\hline 4-6 people & $908(51.7)$ \\
\hline $6+$ people & $341(19.4)$ \\
\hline \multicolumn{2}{|l|}{ Attitude towards Covid-19 } \\
\hline \multicolumn{2}{|l|}{ Self-Isolation } \\
\hline No & $1237(66.7)$ \\
\hline Yes & $564(31.3)$ \\
\hline \multicolumn{2}{|l|}{ Home quarantined due to Covid-19 } \\
\hline No & $1091(60.7)$ \\
\hline Yes & $707(39.3)$ \\
\hline \multicolumn{2}{|l|}{ Do you live alone during COVID-19 } \\
\hline No & $1,624(81.4)$ \\
\hline Yes & $372(18.6)$ \\
\hline
\end{tabular}




\begin{tabular}{|c|c|}
\hline Variables & $N(\%)$ \\
\hline \multicolumn{2}{|c|}{ Compliance during Covid-19 lockdown } \\
\hline \multicolumn{2}{|c|}{ Attended crowded religious events } \\
\hline No & $1097(54.0)$ \\
\hline Yes & $935(46.0)$ \\
\hline \multicolumn{2}{|c|}{ Wore mask when going out } \\
\hline No & $485(23.9)$ \\
\hline Yes & $1547(76.1)$ \\
\hline \multicolumn{2}{|c|}{ Practiced regular Handwashing } \\
\hline No & $762(37.5)$ \\
\hline Yes & $1270(62.5)$ \\
\hline \multicolumn{2}{|c|}{ Covid-19 Risk Perception } \\
\hline \multicolumn{2}{|c|}{ Risk of becoming infected } \\
\hline High & $669(37.2)$ \\
\hline Low & $1128(62.8)$ \\
\hline \multicolumn{2}{|c|}{ Risk of becoming severely infected } \\
\hline High & $466(25.9)$ \\
\hline Low & $1333(74.1)$ \\
\hline \multicolumn{2}{|c|}{ Risk of dying from the infection } \\
\hline High & $349(19.5)$ \\
\hline Low & $1445(80.6)$ \\
\hline \multicolumn{2}{|c|}{ How worried are you because of COVID-19 } \\
\hline worried & $1037(57.5)$ \\
\hline not worried & $766(42.5)$ \\
\hline \multicolumn{2}{|c|}{ How likely do you think COVID-19 will continue in your country } \\
\hline Very likely & $1152(64.0)$ \\
\hline not very likely & $649(36.0)$ \\
\hline \multicolumn{2}{|c|}{ Concern for self and family if COVID-19 continues } \\
\hline Concerned & $1667(94.2)$ \\
\hline Not concerned & $102(5.8)$ \\
\hline \multicolumn{2}{|c|}{ Outcome measure } \\
\hline \multicolumn{2}{|c|}{ COVID caused by $5 G$} \\
\hline No & $1723(92.6)$ \\
\hline Yes & $137(7.4)$ \\
\hline
\end{tabular}

measures. ${ }^{2}$ In a new study conducted in Australia, ${ }^{22}$ researchers found that men and people aged 18-25 were more likely to believe COVID-19 myths particularly, those who were from a non-English speaking background. We found similar associations with young people indicating that significant proportion of younger people (18-28 years) reported that 5G technology was associated with COVID-19 pandemic while those aged between 39 and 48 years were less likely to believe in the $5 \mathrm{G}$ technology myth after adjusting for all potential cofounders. This preponderance of young people may be due to the fact that younger people (aged $18-29$ years) in SSA are more likely to own smartphones compared to older ones aged 50 and older. ${ }^{23}$ There is need to reach young people with health messages particularly, since they are less likely to have symptoms, and as such may not meet testing criteria such as having a sore throat, fever or cough; more likely to have more social contacts through seeing friends more often, which increases their potential for spreading COVID-19, and can potentially be hospitalized with COVID-19 with severe complications in some despite their age.

The study conducted in England observed that endorsement of the coronavirus conspiracy belief was associated with less compliance to government preventive measures. ${ }^{2}$ Although the proportion of participants who held the $5 \mathrm{G}$ myth was less than those who held similar belief in the England study, ${ }^{2}$, it should not be treated lightly especially for the fact that currently there is no end in sight for a medication or vaccine for COVID-19 and the fear of a second wave is staggering. Such myths or conspiracy beliefs in the midst of a pandemic crisis can have far-reaching consequences for the introduction of a vaccine in this region, with belief in anti-vaccine myths being linked to potential non-compliance. $^{21,24}$ 
Table 3. Proportion and unadjusted odds ratio (95\%Confidence intervals, CI) of factors associated with $5 \mathrm{G}$ technology and COVID-19

\begin{tabular}{|c|c|c|c|c|}
\hline Variables & Proportion & Odds Ratio & {$[95 \% \mathrm{Cl}]$} & Pvalue \\
\hline \multicolumn{5}{|l|}{ Demography } \\
\hline \multicolumn{5}{|l|}{ Country of origin } \\
\hline West Africa & 6.3 & 1.00 & & \\
\hline East Africa & 8.4 & 1.38 & {$[0.78,2.44]$} & 0.271 \\
\hline Central Africa & 14.4 & 2.51 & {$[1.61,3.93]$} & $<0.001$ \\
\hline Southern Africa & 5.4 & 0.85 & {$[0.51,1.42]$} & 0.531 \\
\hline \multicolumn{5}{|l|}{ Place of residence } \\
\hline Local & 7.4 & 1.00 & & \\
\hline Diaspora & 8.3 & 1.15 & {$[0.60,2.00]$} & 0.678 \\
\hline \multicolumn{5}{|l|}{ Age category } \\
\hline $18-28$ years & 10.7 & 1.00 & & \\
\hline 29-38 years & 5.6 & 0.50 & {$[0.32,0.79]$} & $<0.001$ \\
\hline $39-48$ years & 3.7 & 0.32 & {$[0.18,0.57]$} & $<0.001$ \\
\hline 49+years & 7.8 & 0.70 & {$[0.41,1.21]$} & 0.202 \\
\hline \multicolumn{5}{|l|}{ Sex } \\
\hline Males & 5.5 & 1.00 & & \\
\hline Females & 9.5 & 1.80 & {$[1.26,2.57]$} & $<0.001$ \\
\hline \multicolumn{5}{|l|}{ Marital Status } \\
\hline Married & 5.7 & 1.00 & & \\
\hline Not married & 8.7 & 1.56 & {$[1.08,2.25]$} & 0.017 \\
\hline \multicolumn{5}{|c|}{ Highest level of Education } \\
\hline Postgraduate Degree & 5.4 & 1.00 & & \\
\hline Bachelor's degree & 8.1 & 1.53 & {$[1.00,2.35]$} & 0.051 \\
\hline Secondary/Primary & 8.8 & 1.69 & {$[1.02,2.80]$} & 0.041 \\
\hline \multicolumn{5}{|l|}{ Employment status } \\
\hline Employed & 5.6 & 1.00 & & \\
\hline Unemployed & 10.9 & 2.08 & {$[1.46,2.96]$} & $<0.001$ \\
\hline \multicolumn{5}{|l|}{ Religion } \\
\hline Christianity & 7.5 & 1.00 & & \\
\hline Others & 6.1 & 0.80 & {$[0.45,1.45]$} & 0.470 \\
\hline \multicolumn{5}{|l|}{ Occupation } \\
\hline Non-health care sector & 7.6 & 1.00 & & \\
\hline Health care sector & 7.4 & 0.96 & {$[0.63,1.47]$} & 0.856 \\
\hline \multicolumn{5}{|l|}{ Number living together } \\
\hline$<3$ people & 6.3 & & & \\
\hline 4-6 people & 8.6 & 1.41 & {$[0.90,2.21]$} & 0.133 \\
\hline $6+$ people & 7.8 & 1.27 & {$[0.73,2.20]$} & 0.406 \\
\hline \multicolumn{5}{|l|}{ Attitude } \\
\hline \multicolumn{5}{|l|}{ Self-Isolation } \\
\hline No & 6.7 & 1.00 & & \\
\hline Yes & 8.4 & 1.29 & {$[0.89,1.87]$} & 0.186 \\
\hline \multicolumn{5}{|c|}{ Home quarantined due to Covid-19 } \\
\hline No & 6.3 & 1.00 & & \\
\hline Yes & 8.7 & 1.43 & {$[0.99,2.05]$} & 0.054 \\
\hline \multicolumn{5}{|c|}{ Compliance with mitigation practices } \\
\hline Attended crowded relig & & & & \\
\hline
\end{tabular}




\begin{tabular}{|c|c|c|c|c|}
\hline Variables & Proportion & Odds Ratio & {$[95 \% \mathrm{Cl}]$} & Pvalue \\
\hline No & 6.5 & 1.00 & & \\
\hline Yes & 8.6 & 1.37 & {$[0.96,1.93]$} & 0.080 \\
\hline \multicolumn{5}{|c|}{ Wore mask when going out } \\
\hline No & 7.3 & 1.00 & & \\
\hline Yes & 7.4 & 1.01 & {$[0.68,1.50]$} & 0.978 \\
\hline \multicolumn{5}{|c|}{ Practiced regular Hand washing } \\
\hline No & 9 & 1.00 & & \\
\hline Yes & 6.6 & 0.71 & {$[0.50,1.01]$} & 0.060 \\
\hline \multicolumn{5}{|l|}{ Risk Perception } \\
\hline \multicolumn{5}{|c|}{ Risk of becoming infected } \\
\hline High & 8.50 & 1.00 & & \\
\hline Low & 6.50 & 0.74 & {$[0.52,1.07]$} & 0.106 \\
\hline \multicolumn{5}{|c|}{ Risk of becoming severely infected } \\
\hline High & 9.00 & 1.00 & & \\
\hline Low & 6.60 & 0.71 & {$[0.49,1.05]$} & 0.085 \\
\hline \multicolumn{5}{|c|}{ Risk of dying from the infection } \\
\hline High & 8.00 & 1.00 & & \\
\hline Low & 7.10 & 0.87 & {$[0.56,1.35]$} & 0.533 \\
\hline \multicolumn{5}{|c|}{ Worried are you because of COVID-19 } \\
\hline Very worried & 7.00 & & & \\
\hline not very worried & 7.40 & 1.05 & {$[0.73,1.50]$} & 0.805 \\
\hline \multicolumn{5}{|c|}{ Concern for self and family if COVID-19 continues } \\
\hline Very concerned & 7.00 & & & \\
\hline Not very concerned & 10.80 & 1.60 & {$[0.83,3.08]$} & 0.158 \\
\hline \multicolumn{5}{|c|}{ Likelihood of COVID-19 continuing in your country } \\
\hline Very likely & 6.30 & 1.00 & & \\
\hline not very likely & 9.10 & 1.50 & {$[1.05,2.15]$} & 0.027 \\
\hline
\end{tabular}

Variables with confidence intervals CI that include ' 1 ' were not statistically significant in the model.

However, the present study could not corroborate these fears as participants, who held the myth that $5 \mathrm{G}$ was linked to the coronavirus pandemic had similar rate of compliance with the precautionary measures put in place to minimize the spread of the infection compared with those who did not hold the belief. A study conducted in England observed that endorsement of the coronavirus conspiracy belief was associated with non-compliance with government preventive measures, ${ }^{2}$, with another worrying phenomenon being that, myths are never benign and people who hold one myth are more likely to believe other unrelated ones. ${ }^{2,25}$ In this study, participants who thought the infection will not continue after the lockdown were more likely to associate it with the $5 \mathrm{G}$ myth. Our suggestion therefore is that there must be concerted regional and global educational campaigns to recondition the minds of the populace before the introduction of a vaccine. Freeman et al. ${ }^{2}$ did not only observe a significant association between the myths and noncompliance with preventive guidelines but also the participants' skepticism to undertake future tests and vaccinations.

The differing levels of belief in the $5 \mathrm{G}$ myth among participants across the SSA sub-region as well as between other studies may reflect varying degrees of drivers of the myths such as mistrust ${ }^{26}$ and other related consequences. Social identity including religion and nationality are known to promote the belief of myths. ${ }^{27}$ Surveys in the USA and the United Kingdom found strong association between holding the myth and national narcissism (the trust in the greatness of one's country) such that people who scored high in national narcissism were more likely to believe and disseminate myths about COVID-19. ${ }^{28}$. Unlike a previous study, ${ }^{2}$ the current study did not find any significant association between the $5 \mathrm{G}$ myth and the different religious groups. This is probably due to the disproportionate over-representation of Christians over other religious groups in this study.

Factors such as lower income and education levels, ${ }^{29}$ low social standing ${ }^{30}$ and less ability to analyze ${ }^{31}$ have all been linked to holding to myths. It was therefore not surprising that in the present study, with everything held equal, participants who have a bachelor's degree or less and those who were unemployed were more likely to believe that the $5 \mathrm{G}$ technology was associated with the outbreak of the coronavirus infection. Further ramifications are that the worsening economic conditions resulting from the coron- 
Table 4. Predictors of the association between belief in 5G technology and COVID-19.

\begin{tabular}{|c|c|c|c|}
\hline Variables & Predictors & & \\
\hline Demography & Odds Ratio & {$[95 \% \mathrm{Cl}]$} & $P$ value \\
\hline \multicolumn{4}{|l|}{ Country of origin } \\
\hline West Africa & 1.00 & & \\
\hline East Africa & 1.30 & {$[0.70,2.41]$} & 0.406 \\
\hline Central Africa & 2.03 & {$[1.25,3.30]$} & 0.004 \\
\hline Southern Africa & 0.79 & {$[0.46,1.35]$} & 0.390 \\
\hline \multicolumn{4}{|l|}{ Age category } \\
\hline 18-28years & 1.00 & & \\
\hline $29-38$ & 0.59 & {$[0.34,1.05]$} & 0.073 \\
\hline $39-48$ & 0.45 & {$[0.22,0.94]$} & 0.035 \\
\hline 49+years & 1.07 & {$[0.55,2.10]$} & 0.835 \\
\hline \multicolumn{4}{|l|}{ Sex } \\
\hline Males & 1.00 & & \\
\hline Females & 1.59 & {$[1.09,2.34]$} & 0.017 \\
\hline \multicolumn{4}{|c|}{ Employment status } \\
\hline Employed & 1.00 & & \\
\hline Unemployed & 1.64 & {$[1.00,2.70]$} & 0.049 \\
\hline \multicolumn{4}{|l|}{ Risk perception } \\
\hline \multicolumn{4}{|c|}{ Risk of becoming infected } \\
\hline High & 1.00 & & \\
\hline Low & 0.64 & {$[0.43,0.94]$} & 0.023 \\
\hline \multicolumn{4}{|c|}{ How likely do you think COVID-19 will continue in your country? } \\
\hline \multicolumn{4}{|l|}{ Very likely } \\
\hline not very likely & 1.57 & {$[1.07,2.31]$} & 0.022 \\
\hline
\end{tabular}

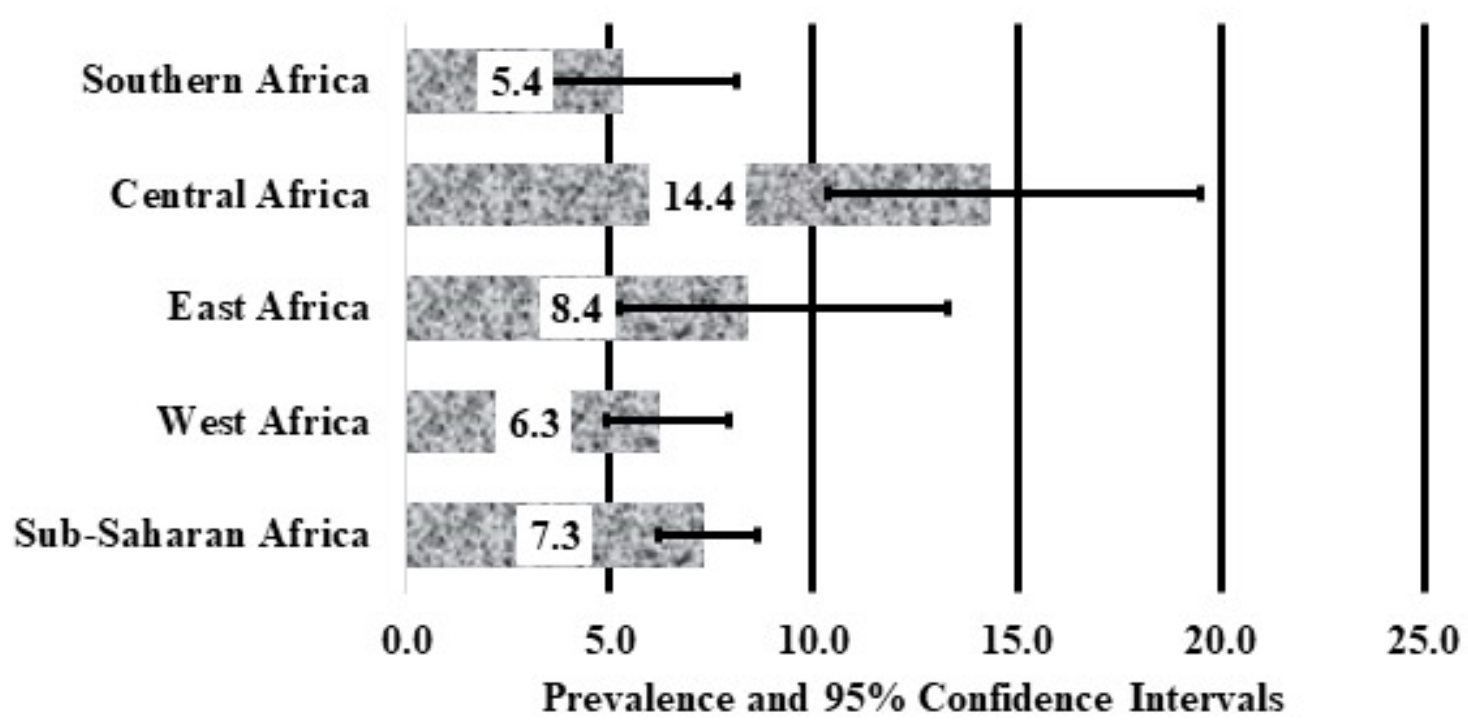

Figure 1. Regional proportion and 95\% Confidence interval of participants who associated 5G with COVID-19 in SubSaharan Africa. 
avirus counter-measures can trigger or aggravate contiguous myths relating to the pandemic and further derail future efforts towards the introduction of medical interventions through tests and vaccinations.

The finding that that after controlling for all potential cofounders, participants who did not think that the infection will continue after the lockdown despite the lack of vaccine were more likely to associate the infection with the $5 \mathrm{G}$ technology validates the propositions of the health belief model (HBM). Constructs of HBM, specifically perceived susceptibility and perceived severity postulate that individuals will take actions to prevent or reduce a health problem if they perceive themselves as susceptible to the health problem or if they perceive the health problem will have serious consequences. ${ }^{20}$ Perhaps the perception that the pandemic was being engineered by a telecommunication technology also led to their belief that they were less susceptible to the disease or that it would have trivial or minor health consequence.

Since many of the SSA countries still do not have the $5 \mathrm{G}$ technology, it is unlikely to accurately predict the impact of such belief on their attitude towards the $5 \mathrm{G}$ technology, however, early educational campaigns prior to the launch of the technology is recommended. Ensuring that people understand the benefits of the technology and how this can improve connectivity of people and access to information will facilitate the introduction and dissuade such belief. In addition, further studies targeting SSA populations most affected by this belief are therefore recommended.

In considering the results from this study and the implications, the following limitations in the study should be noted. It is important that researchers interpret the finding that education is linked to the myth of $5 \mathrm{G}$ technology with caution, particularly as the participants in this study are biased regarding education. Given the difficulty of obtaining random sample from the study population, a convenient sampling technique was employed and this may affect the generalizability of the study results. However, during the lockdown, this was the only feasible way of collecting data from participants and this study provides an insight on the subject matter in the population surveyed. The data may be skewed towards those who may have access to internet and regularly use the social media platforms used in distributing the survey questionnaire. Being an electronic survey, residents in SSA who do not have access to the internet may have been unduly excluded from the study, which may account for the preponderance of the younger age group (over 65\% were 38 years or younger). Furthermore, deploying the questionnaire in English language also excluded the non-English speaking residents in SSA such as the Frenchspeaking people from the Central and West African region. When interpreting the present results, researchers should be cautious especially as non-response is not known most probably because, we do not know who received an invita- tion to participate. In addition, as this was a cross-sectional study, the estimates reported may have overestimated or underestimated 5G myths linked to COVID-19 in SSA and causality cannot be assumed.

\section{CONCLUSIONS}

In summary, this study demonstrated that $7.4 \%$ of adult participants associated $5 \mathrm{G}$ technology with the outbreak of COVID-19, especially young people, females, those living in Central African countries and participants who were unemployed at the time of this study. Public health interventions including health education strategies to address the myth that $5 \mathrm{G}$ was linked COVID-19 pandemic in SSA are needed and such intervention should target these participants including those who do not believe that COVID-19 pandemic will continue in their country, in order to minimize further spread of the disease in the region.

\section{AVAILABILITY OF DATA AND MATERIAL}

Additional information such as unidentified raw data can be obtained following reasonable request from the corresponding author.

\section{FUNDING}

None

\section{AUTHORSHIP CONTRIBUTIONS}

All authors contributed to the design and conduct of study, and writing of manuscript.

\section{COMPETING INTERESTS}

The authors completed the Unified Competing Interest form at www.icmje.org/coi_disclosure.pdf (available upon request from the corresponding author), and declare no conflicts of interest.

\section{CORRESPONDENCE TO}

Godwin Ovenseri-Ogbomo

Department of Optometry

Faculty of Life Sciences

University of Benin

Benin, Nigeria

godwin.ovenseri-ogbomo@uniben.edu

Submitted: August 29, 2020 GMT, Accepted: October 02, 2020

GMT 


\section{REFERENCES}

1. Ahmed W, Vidal-Alaball J, Downing J, López Seguí F. COVID-19 and the 5G Conspiracy Theory: Social Network Analysis of Twitter Data. J Med Internet Res. 2020;22(5):e19458. doi:10.2196/19458

2. Freeman D, Waite F, Rosebrock L, et al. Coronavirus conspiracy beliefs, mistrust, and compliance with government guidelines in England. Psychol Med. May 2020:1-13. doi:10.1017/s00332917 20001890

3. Russell CL. $5 \mathrm{G}$ wireless telecommunications expansion: Public health and environmental implications. Environ Res. 2018;165:484-495. doi:1 $\underline{0.1016 / j . e n v r e s .2018 .01 .016}$

4. Simkó M, Mattsson M-O. 5G Wireless Communication and Health Effects-A Pragmatic Review Based on Available Studies Regarding 6 to 100 GHz. Int J Environ Res Public Health. 2019;16(18):3406-3429. doi:10.3390/ijerph16183406

5. Johansen C. Electromagnetic fields and health effects-epidemiologic studies of cancer, diseases of the central nervous system and arrhythmia-related heart disease. Scand J Work Environ Health. 2004;30:1-80.

6. Di Ciaula A. Towards 5G communication systems: Are there health implications? International Journal of Hygiene and Environmental Health. 2018;221(3):367-375. doi:10.1016/i.ijheh.2018.01.011

7. Belpomme D, Hardell L, Belyaev I, Burgio E, Carpenter DO. Thermal and non-thermal health effects of low intensity non-ionizing radiation: An international perspective. Environmental Pollution. 2018;242:643-658. doi:10.1016/j.envpol.2018.07.019

8. Kostoff RN, Heroux P, Aschner M, Tsatsakis A. Adverse health effects of $5 \mathrm{G}$ mobile networking technology under real-life conditions. Toxicology Letters. 2020;323:35-40. doi:10.1016/j.toxlet.2020.0 $\underline{1.020}$

9. Vanderstraeten J, Verschaeve L. Biological effects of radiofrequency fields: Testing a paradigm shift in dosimetry. Environmental Research. 2020;184:109387. doi:10.1016/i.envres.2020.109387

10. WHO. 5G networks and health. 2020. https://ww w.who.int/news-room/q-a-detail/5g-mobile-network s-and-health. Accessed May 14, 2020.
11. Organization WH. Coronavirus disease (COVID-19) advice for the public: Myth busters. 2020. https://www.who.int/emergencies/diseases/novel-cor onavirus-2019/advice-for-public/myth-busters? Accessed June 14, 2020.

12. Harsine K. Is Africa ready for 5G? 2019. https://w ww.dw.com/en/is-africa-ready-for-5g. Accessed June $14,2020$.

13. Casazza K, Fontaine KR, Astrup A, et al. Myths, presumptions, and facts about obesity. $N$ Engl J Med. 2013;368(5):446-454. doi:10.1056/nejmsa1208051

14. Viehbeck SM, Petticrew M, Cummins S. Old myths, new myths: Challenging myths in public health. Am J Public Health. 2015;105(4):665-669. do i:10.2105/ajph.2014.302433

15. Fiaveh DY. Condom Myths and Misconceptions: The Male Perspective. Global J Med Res. 2012;12:43-50.

16. Cohen SA. Abortion and Mental Health: Myths and Realities. Guttmacher Policy Review. 2006;9:8-16.

17. Clift K, Rizzolo D. Vaccine myths and misconceptions. Journal of the American Academy of PAs. 2014;27(8):21-25. doi:10.1097/01.jaa.000045187 $\underline{3.94189 .56}$

18. Davidson M. Vaccination as a cause of autismmyths and controversies. Dialogues Clin Neurosci. 2017;19(4):403-407. doi:10.31887/dens.2017.19.4/mda vidson

19. Control CfD. Implementation of Mitigation Strategies for Communities with Local COVID-19 Transmission. In: Control CfD, ed. Centers for Disease Control. ; 2020:1-10.

20. Jones CL, Jensen JD, Scherr CL, Brown NR, Christy $\mathrm{K}$, Weaver J. The Health Belief Model as an explanatory framework in communication research: Exploring parallel, serial, and moderated mediation. Health Commun. 2015;30(6):566-576. doi:10.1080/10 410236.2013.873363

21. Jolley D, Douglas KM. The effects of anti-vaccine conspiracy theories on vaccination intentions. Tripp R, ed. PLoS ONE. 2014;9(2):e89177. doi:10.1371/journ al.pone.0089177 
22. Pickles K, Cvejic E, Nickel B, et al. COVID-19: Beliefs in misinformation in the Australian community. medRxiv. August 2020. doi:10.1101/202 $\underline{0.08 .04 .20168583}$

23. Silver L, S C. Internet Connectivity Seen as Having Positive Impact on Life in Sub-Saharan Africa. Washington D C: Pew-Research Center; 2018.

24. Jolley D, Douglas KM. Prevention is better than cure: Addressing anti-vaccine conspiracy theories. $J$ Appl Soc Psychol. 2017;47(8):459-469. doi:10.1111/ja sp. 12453

25. Swami V, Chamorro-Premuzic T, Furnham A. Unanswered questions: A preliminary investigation of personality and individual difference predictors of 9/ 11 conspiracist beliefs. Appl Cognit Psychol. 2010;24(6):749-761. doi:10.1002/acp.1583

26. Goreis A, Voracek M. A Systematic Review and Meta-Analysis of Psychological Research on Conspiracy Beliefs: Field Characteristics, Measurement Instruments, and Associations With Personality Traits. Front Psychol. 2019;10. doi:10.338 9/fpsyg.2019.00205
27. Douglas KM, Uscinski JE, Sutton RM, et al. Understanding Conspiracy Theories. Political Psychology. 2019;40(S1):3-35. doi:10.1111/pops. 1256 $\underline{8}$

28. Sternisko A, Cichocka A, Cislak A, Van Bavel JJ. Collective narcissism predicts the belief and dissemination of conspiracy theories during the COVID-19 pandemic. May 2020. doi:10.31234/osf.io/4 c6av

29. Douglas KM, Sutton RM, Callan MJ, Dawtry RJ, Harvey AJ. Someone is pulling the strings: Hypersensitive agency detection and belief in conspiracy theories. Thinking \& Reasoning. 2016;22(1):57-77. doi:10.1080/13546783.2015.105158 $\underline{6}$

30. Freeman D, Bentall RP. The concomitants of conspiracy concerns. Soc Psychiatry Psychiatr Epidemiol. 2017;52(5):595-604. doi:10.1007/s00127-0 17-1354-4

31. Swami V, Voracek M, Stieger S, Tran US, Furnham A. Analytic thinking reduces belief in conspiracy theories. Cognition. 2014;133(3):572-585. doi:10.101 6/j.cognition.2014.08.006 


\section{SUPPLEMENTARY MATERIALS}

\section{Online Supplementary Document}

Download: https://www.joghr.org/article/17606-factors-associated-with-the-myth-about-5g-network-duringcovid-19-pandemic-in-sub-saharan-africa/attachment/45955.docx 